\title{
Poverty, inequality and health: issues relevant to South Asia
}

\section{Saroj Jayasinghe}

A recent special issue of British Medical Journal emphasised the situation of poverty and health in South Asia [1]. The region has half the population below the poverty line and burdens from communicable and noncommunicable diseases, injuries, tobacco use and malnutrition. It is also the "the poorest, most illiterate, most malnourished, least gender-sensitive and most deprived region of the world" [2]. The article gives an overview of a few selected areas related to poverty, inequality and ill health, which are especially relevant to health workers in southern Asia.

\section{What is poverty?}

The simplest definition of the poor is "having little money or means" [3]. However, poverty has several facets such as social exclusion and low self-esteem, though the emphasis is often on money, materials or assets. Relative poverty and absolute poverty are two other concepts used when defining the term. In the former, poverty is defined in relation to the standards that exist elsewhere in society. For example, the cut-off could be arbitrarily set at the level of the bottom three income deciles. This approach gives little information on poverty profiles over time because there is always a bottom $30 \%$ of the population, irrespective of changes in living standards. In contrast, absolute poverty considers whether essential or basic human physical subsistence needs (e.g. food, safe drinking water, sanitation facilities, health, shelter, education, information and access to social services) are being met or not [4]. For convenience, these essential needs are often expressed as daily-recommended nutrition allowances in calories per person. Thus, poverty is assumed to be present if a household is unable to purchase the daily-required 
calories. The main drawback of this method is that it ignores individual variation in calorie needs, genetic differences and micronutrients [5].

\section{Measuring poverty}

Valid and reliable measurement of the economic dimension of poverty would enable effective interventions to reach the needy and therefore save lives and reduce misery. Economists often use income levels to define poverty. In developing countries, income is not always reliable or available. In such settings, researchers use consumption data to obtain information on how much people spend for food, housing, health care, education and other items.

Sri Lanka has recently developed an "absolute" poverty line using the expenditures required to buy a basket of foods to get the required calorie intake and a minimum of non-food items [6]. For purposes of international comparisons, poverty is often defined as a daily individual income below US $\$ 1$, adjusted for differences in purchasing power between countries. Other proxy measures of poverty are used to identify relative deprivation in geographic areas (for example, the Jarman Index developed in the UK to identify general practitioners serving deprived areas) [7].

\section{Poverty as an aetiological factor in illness and prognosis}

Irrespective of the definition used, there is a close link between poverty and illness. The spiral of poverty as a result of a chronic illness or premature death of a breadwinner is common in South Asia. What is less well appreciated is that poverty and low income can result in illness. This aetiological link is not limited to communicable diseases, but extends even to non-communicable diseases and injuries. Thus, the poor easily become victims of a vicious cycle of events, with poverty promoting illness and illness in turn precipitating, maintaining or worsening poverty.

The evidence for the close relationship between poverty and ill health is available from inter-country and within country studies [8]. Generally, poor countries have worse health outcomes when compared to their richer counterparts and a similar relationship is seen also within countries and communities. At a global level, the ratio of the age specific death rates between the poorest $20 \%$ and the richest $20 \%$ is as high as 10 for the age group 5-14 years [9]. Even in developed countries such as the UK, higher morbidity from childhood malnutrition and communicable diseases are seen in poorer social classes [10].

A less obvious link exists between poverty and noncommunicable diseases (such as ischaemic heart disease). Several studies have shown that lower income groups are vulnerable and have a poorer prognosis from diabetes, stroke and hypertension. [11-13]. Furthermore, common risk factors (e.g. smoking, hypertension, cholesterol levels) failed to account for the higher rates of coronary heart disease among the lower employment grades [12].

Three groups of hypotheses are used to explain the association between poverty and poor health outcomes: the poor have a general susceptibility to illnesses as a result of more life related stresses; adverse behavioural patterns (e.g. smoking) are commonest in the poor; socially patterned environmental exposures across the life span resulting in varying health outcomes [14 ].

The last of the aforementioned hypotheses has gained acceptance and there is a large body of literature to support it. Forsdhal initially proposed the association between low socioeconomic class in early life and later illness [15]. This theory was further developed by Baker to include fetal life as a determinant of adult disease, a critical factor in the developing non-communicable disease epidemic in south Asia [16]. He suggested that maternal malnutrition resulted in retarded fetal growth which, when combined with subsequent compensatory growth predisposed to non-communicable diseases such as hypertension and coronary artery disease. It is likely that the effect of socioeconomic circumstances on mortality and disease risk acts throughout life (i.e. life course influences) at varying intensities. For example, poverty at birth increases the risk of hypertension while current poverty is positively associated with higher rates of smoking [14]. The end result is that the poor when compares to the rich, are at higher risk of developing several non-communicable diseases from a series of adverse environmental factors during the course of their lives.

\section{The links between inequality and illness: more than simple poverty}

The relationship between poverty and illness becomes still more complicated by the observation that income inequality, irrespective of the level of poverty has a negative impact on health outcomes [17]. In other words, if two countries have similar average income levels, the one with wider income disparities has poorer health outcomes than the other with less disparity (or more equity). This may partly explain the relatively good health indices of Sri Lanka and Kerala, because both have less income disparities (than other countries in the region) with a strong tradition of welfare, pro-equity measures and socialist policies.

\section{IIIness at a household level: patterns in utilisation of services and financial coping}

Community surveys indicate that in addition to illness patterns, utilization of health services vary across income levels. For example, the percentage of persons seeking 'western' medical treatment from government hospitals decreased with income, and the percentage seeking treatment from private practitioners increased with household income [18]. 
Researchers have attempted to describe and analyse how illness could affect household functioning [19, 20]. Households respond by three main ways: reducing essential expenditures (e.g. for food), choosing less costly and ineffective medical care, or a combination of these strategies. Some households are pushed into poverty because of illness, as a result of 'catastrophic expenditures'. Identifying this level of expenditures is important in order to plan suitable safety nets or financial assistance programmes. What proportion of household income spent on health is considered catastrophic? Studies from Thailand have shown that the poor are more likely to have to pay for accessing health services from their own household income than richer people $[19,20]$. One multicountry study identified catastrophic expenditures at $40 \%$ or above of total household income, whereas others have used 5-20\% [19].

\section{Poverty, inequality health in South Asia: an agenda for action}

It is increasingly becoming evident that the poor are at risk of acute as well as chronic illnesses. South Asian health sector needs to meet this challenge of a double burden in the region. Sri Lanka appears to have taken a lead in certain areas by having a tradition of welfare measures from 1940's, which included food subsidies for the poor and universal access to education. Our health system was able to reach the poor with an extensive network of preventive services, targeting maternal and child-health, and services accessible free of charge at point of delivery to the user [21].

However, more needs to be done in the region (as well as in Sri Lanka). We need to target specific programmes to the poorer and marginalised in the society and introduce methods to reduce the growing inequities in access to health care. Pro-poor policies would include increased allocation of material, financial and human resources to poorer areas, improving the quality of service provided to the poor and strengthening preventive health services [22].

Health care workers have to be sensitive to the links between poverty and health, and promote the formation of systems (formal and informal) to support the needs of the poor in their care. Unlike European countries, most of the former colonies in South Asia lack a strong formal social support system and instead rely on the extended family to care for the chronically ill, the differently-abled and the elderly. These informal arrangements are rapidly eroding with more nuclear families, female employment and decreasing family size. The end result is that households have to bear the burden of severe illness in a family member. This emphasises the need for policymakers in South Asia to develop formal social safety nets (e.g. social insurance, high quality health at zero user charge for the needy, forms of community insurance).

Researchers need to disaggregate health data based on socioeconomic status and spatial data to identify deprived areas, in order to describe their relationship to health status and target interventions. More innovative and user-friendly measures of poverty appropriate to South Asia have to be developed (for example, using assets of households as proxy measures of socioeconomic status [23]).

Other measures at national (and even regional) levels would help to improve the situation. Though these decisions are outside the health sector, the medical profession should lobby for such changes in governments by demonstrating their health and economic benefits of such policies. For example, curtailing the military expenditures of our countries and investing the "peace dividends' in primary education, basic health and social safety nets [2].

\section{Acknowledgements}

I thank Dr. Amala de Silva for her advice in preparation of this paper.

\section{References}

1. Smith Richard. Towards a global social contract. British Medical Journal 2004; 328: 41-3.

2. Mahbub ul Haq, ed. Human Development in South Asia. Karachi: Oxford University Press, 1997.

3. Liebeck H, Pollard E, eds. The Oxford English Mini Dictionary. 4th ed. Calcutta: Oxford University Press, 1996.

4. Gordon D, Spicker P, eds. The International Glossary on Poverty. London: Zed Books Ltd., 1999.

5. Osmani SR. Nutrition and economics of food: Implications of some recent controversies. In: Dreze J, Sen A, eds. The Political Economy of Hunger. Oxford: Oxford University Press, 1990: 274-94

6. Official Poverty Line for Sri Lanka. http:// www.statistics.gov.lk/poverty/OfficialPovertyLineBuletin.pdf (accessed 2 August 2004).

7. Jarman B. Identification of under-privileged areas. British Medical Journal 1983; 286: 1705-9.

8. Gwatkin DR, Guillot M, Heuveline P. The burden of disease among the global poor. Lancet 1999; 354: 586-9.

9. Gwatkin DR. Poverty and inequalities in health within developing countries: filling the information gap. In: Leon D, Walt G, eds. Poverty Inequality and Health: an International Perspective. Oxford: Oxford University Press, 2000: 217-46.

10. Townsend P, Davidson N, eds. Inequalities in Health, the Black Report and the Health Divide. 2nd ed. London: Penguin Books, 1992.

11. Taylor FC, Ascione R, Rees K, Narayan P, Angelini GD. Socioeconomic deprivation is a predictor of poor postoperative cardiovascular outcomes in patients undergoing coronary artery bypass grafting. Heart 2003; 89: 1062-6. 
12. Davey Smith G. Down at heart-the meaning and implications of social inequalities in cardiovascular disease. Journal of the Royal College of Physicians of London 1997; 31: 414-23.

13. Eachus J, Williams M, Chan P, et al. Deprivation and cause specific morbidity: evidence from the Somerset and Avon survey of health. British Medical Journal 1996; 312: 287-92.

14. Davey Smith G, Gunnell D, Ben-Shlomo Y. Life-course approaches to socio-economic differentials in cause-specific adult mortality. In: Leon D, Walt G, eds. Poverty Inequality and Health: an International Perspective. Oxford: Oxford University Press, 2000: 88-124.

15. Forsdahl A. Living conditions in childhood and subsequent development of risk factors for arteriosclerotic heart disease. The Cardiovascular Survey in Finnmark 197475. Journal of Epidemiology and Community Health 1978; 32: 34-7.

16. Robinson R. The fetal origins of adult disease: no longer a hypothesis and may be critically important in south Asia. British Medical Journal 2001; 322: 375-6.
17. Xu K, Evans DB, Kawabata K, Zeramdini R, Klavus J, et al. Household catastrophic health expenditure: a multicountry analysis, Lancet 2003; 362: 111-7

18. Report on Consumer Finances and Socioeconomic Survey of Sri Lanka 1996/97, part 1, The Central Bank of Sri Lanka, 1998.

19. Pannarunothai S, Mills A. The poor pay more: health related inequality in Thailand. Social Science and Medicine 1997; 44: 1781-90.

20. Wilkinson RG. Income distribution and life expectancy. British Medical Journal 1992; 304: 165-8.

21. Leon DA, Walt G, Gilson L. International perspectives on health inequalities and policy. British Medical Journal 2001; 322: 591-4.

22. Fernando- Lavaenz M, Amala de Silva. Poverty, Transition and Health: A Rapid Health System Analysis. Colombo: World Health Organization, 2002.

23. Gwatkin D, Rutstein S, Johnson K, Pande R, Wagstaff A. Socioeconomic Differences in Health, Nutrition and Population in India. Washington: HNP/Poverty Thematic Group of The World Bank, 2002.

Associate Professor, Department of Clinical Medicine, Faculty of Medicine, University of Colombo, Colombo, Sri Lanka. Correspondence: Tel: +94-11-2695300, e-mail: <sarojoffice@yahoo.com> (Competing interests: none declared).

\section{Homosexuality}

Homosexuality is assuredly no advantage, but it is nothing to be ashamed of, no vice, no degradation, it cannot be classified as an illness; we consider it to be a variation of the sexual function, produced by a certain arrest of the sexual development. It is a great injustice to persecute homosexuality as a crime-and a cruelty too.

Sigmund Freud 